\title{
Challenges for the adoption of ICT for diabetes self- management in South Africa
}

\section{Fazlyn Petersen (D) | Afeefa Brown | Shaun Pather | William D. Tucker}

Department of Information Systems, University of the Western Cape, Cape Town, South Africa

\section{Correspondence}

Fazlyn Petersen, Department of Information Systems, University of the Western Cape,

Cape Town, South Africa.

Email: fapetersen@uwc.ac.za

Funding information

South African National Research Foundation, Grant/Award Number: 116819

\begin{abstract}
The increasing disease burden in developing countries inhibits the provision of quality care to citizens. However, the increased availability of information communication and technology (ICT) tools makes this a viable option for inclusion in primary health care. Even so, barriers are impeding the successful adoption and usage of ICT tools in health care contexts. This research focuses on one such context to identify the challenges and barriers for the adoption of ICT tools for diabetes self-management in the Western Cape province of South Africa.

The extended technology acceptance model (TAM) and four factors (educational, technological, economic, and sociocultural factors) were identified as a basis for investigation. Evidence was gathered from a sample of 131 diabetic patients using semistructured interviews. These factors, together with TAM constructs, explore how patients interact with ICT and their attitudes towards the use of ICT for diabetes self-management. The results indicate that all four factors form barriers to ICT adoption for diabetes self-management. These findings provide a basis to inform how future interventions at the primary health care level may be developed to overcome the identified barriers in efforts to integrate ICT tools into diabetic patients' daily selfmanagement routines.
\end{abstract}

\section{KEYWORDS}

electronic health, information communication and technology for development (ICT4D), mobile health, technology acceptance model (TAM)

\section{1 | INTRODUCTION}

While noncommunicable diseases (NCDs) are the preeminent cause of death worldwide, more than $40 \%$ of these deaths are premature and avoidable (Zhao, Freeman, \& Li, 2016). The increases in the number of patients with NCDs, such as diabetes, can be attributed to too little or too much sleep, sedentary lifestyles, unhealthy diets, and obesity (Bourne, Lambert, \& Steyn, 2002; Müller, Alley, Schoeppe, \& Vandelanotte, 2016; Schoeppe et al., 2016; Tan, Chapman, Cedernaes, \& Benedict, 2018). According to the International Diabetes Federation (IDF), Africa has an estimated 15.5 million people with diabetes mellitus and the highest percentage (69.2\%) of undiagnosed people (IDF, 2018). The statistics for South Africa show similar trends. According to IDF (2018), there were 1826100 cases of diabetes in South Africa in 2017. The national diabetes prevalence is estimated at $8.39 \%$, with diabetes-related deaths accounting for 68977 cases.

The prevalence of diabetes is comparable with other low- and middle-income countries (LMIC), where the burden of disease is disproportionate to higher income countries (Pullar et al., 2018). These prevalent inequalities in diabetes are aggravated by variances in lifestyle (Mutyambizi, Booysen, Stokes, Pavlova, \& Groot, 2019). Critical shortages of health professionals and resources in public health sectors are primarily responsible 
for the unavailability and low quality of service received by persons with chronic diseases (Beratarrechea, Moyano, Irazola, \& Rubinstein, 2017). As a consequence, health care systems in these countries are beset with immense challenges for providing quality care (Beratarrechea et al., 2017).

Given the scenario of limited resources in health care systems, the use of information communication and technology (ICT) for medical self-care has become an increasingly popular topic in literature (Bellei, Biduski, Cechetti, \& De Marchi, 2018; Bodenheimer, Lorig, Holman, \& Grumbach, 2002; Gammon, Berntsen, Koricho, Sygna, \& Ruland, 2015; McMillan, Kirk, Hewitt, \& Macrury, 2017; Nundy et al., 2012; Pullar et al., 2018). In the case of diabetes self-care, seven behaviours form the basis of diabetes self-management, namely, healthy eating, being active, blood glucose monitoring, taking medication, problem-solving, healthy coping, and reducing risks (American Association of Diabetes Educators, 1997).

Research describing the use of ICT as an enabler for self-management of tasks performed by the patient includes the use of the internet (47\%), mobile phones (32\%), telemedicine (12\%), and decision support techniques (9\%) (El-Gayar, Timsina, Nawar, \& Eid, 2013). ICT tools can be used to address risk factors such as tobacco use, diet, and physical inactivity (World Health Organization, 2016; Zhao et al., 2016), through the use of lifestyle modification interventions to increase physical activity and reduce smoking, for example (Rehman et al., 2017). There are several examples of how ICTs may be beneficial for diabetes self-management. The internet, for example, is useful for tasks such as sending clinical information (glucose levels and medication usage) to clinicians as well as obtaining feedback on health-related issues (Cotter, Durant, Agne, \& Cherrington, 2014). Mobile phones can be used for uploading glucose levels through integration with a glucometer (a device for testing blood glucose levels) as well as messaging clinicians (El-Gayar et al., 2013). Telemedicine delivers health services-such as interactive, consultative, and diagnostic services-through the use of telecommunications (Faruque et al., 2017).

It has been found that the use of mobile phones for health ( $\mathrm{m}$-health) can reduce premature deaths by delivering effective interventions (Zhao et al., 2016). However, although the use of various forms of ICT shows promise in terms of achieving health outcomes, this has been tested predominantly in patients in developed countries (Ariani, Koesoema, \& Soegijoko, 2017), whereas in LMICs, where the number of patients with diabetes is increasing rapidly with a high mortality rate, there is a greater need for interventions. However, in spite of the availability of m-health applications for diabetes self-management, uptake and continued use is low (Deacon, Chee, Chang, \& Harbourne, 2017). Research indicates that there is unequal use of ICT, such as m-health in "racial or ethnic minorities, older adults, and persons with lower health literacy" (Nelson et al., 2016, p. 12). Therefore, achieving health-related developmental goals by improving diabetes self-management through the use of ICT should take into consideration country-specific factors (Ariani et al., 2017; Waehama, Mcgrath, Korthaus, \& Fong, 2014), including sociocultural beliefs, income, and education levels (Venkatesh, Thong, \& Xu, 2016). These demographic factors are dominant in diverse populations suffering from significant inequalities and forms of technological exclusion (Gillwald, Mothobi, \& Rademan, 2017).

Such demographics are characteristics of the Western Cape, a province in South Africa, which serves as the geographical context in which challenges regarding $\mathrm{m}$-health adoption and use was studied, as diabetes is the leading cause of death (6.8\%) in this province (Statistics South Africa, 2016a). The province has a history of racial segregation where non-white residents were moved from the city centre into township areas, commonly referred to as the Cape Flats (South African History Online, 2011). Approximately 63\% of households in the Khayelitsha and Mitchells Plain, two areas situated in the Cape Flats, have incomes of less than R4166 per month (approximately $\$ 296$ ), of which $16.5 \%$ have no income whatsoever (Western Cape Government, 2017a).

Additionally, a large percentage (89.6\%) of Western Cape residents still do not have access to the internet at home (Statistics South Africa, 2018). Therefore, the resulting digital divide between rich and poor is staggering (Gillwald et al., 2017). The digital divide may impact the achievement of diabetes self-management as access to information is a critical component for effective management of chronic conditions (Omisakin \& Purity Ncama, 2011). Although there is a prevailing digital divide in the Western Cape, issues of access to broadband internet are being addressed, especially in areas near the Cape Metro. In Khayelitsha and Mitchells Plain, for example, the city has been making affordable Wi-Fi available through its Smart Cape Programme (Western Cape Government, 2017b). Even though the problem of access to the internet is improving, there is limited research into the adoption and use of ICT by diabetic patients residing in South Africa (Petersen, Pather, \& Tucker, 2018).

Therefore, this research provides additional insight into that domain as the objective of this paper is to investigate the challenges related to the adoption of ICT for diabetes self-management. The investigation was conducted on a select population in the Western Cape province of South Africa, a populace suffering from a growing diabetes problem, to answer the research question: "What factors form barriers to ICT adoption for diabetes self-management?"

The remainder of the paper is duly organised: The next section introduces the theoretical framework based on the extended technology acceptance model. This is followed in Section 3 by an overview of the research design, sampling, and method for collection of qualitative evidence. The findings are then presented in Section 4, describing ICT adoption perceptions of diabetic patients and the associated environmental barriers in respect of $\mathrm{m}$-health. Section 5 summarises the findings, discusses the limitations of the study, and presents the recommended future work.

\section{2 | THEORETICAL FRAMEWORK}

Models for user adoption demonstrate that an individual's reaction to information technology drives the intention to use ICT, such as m-health. The user's behavioural intention then determines the actual use. Research also proves that the actual use of ICT influences an individual's reaction 
(Venkatesh, Morris, Davis, \& Davis, 2003). For example, if using ICT is slow and cumbersome, this will likely influence an individual to use it less frequently and to a lesser extent, or in other words, not as often and not as much (Venkatesh et al., 2003).

\section{1 | Well-known adoption constructs}

There are four well-known technology adoption models that form the basis of most of the technology adoption literature. The four prominent models are summarised in Figure 1 and then discussed in turn.

The aim of the theory of reasoned action (TRA) is "to develop a theory that could predict, explain, and influence human behaviour" (Alshehri, 2012, p. 46) within their social context (Harvey \& Lawson, 2009). Its core constructs focus on key beliefs formulating attitudes toward behaviour. Attitude refers to "an individual's positive or negative feelings about performing the target behaviour". Subjective norm refers to "the person's perception that most people who are important to him think he should or should not perform the behaviour in question" (Fishbein \& Ajzen, 1975). Subjective norm is determined by an "individual's perceptions of social normative pressures (eg, normative beliefs)" (Sun, Wang, Guo, \& Peng, 2013).

TRA was used to predict the effect of the implementation on dietary and physical activity adherence in patients with non-insulin-dependent diabetes in two studies (Didarloo et al., 2012; Kurnia \& Rama, 2017). In explaining regimen compliance in diabetic patients, a relationship between intention and behaviour was identified, with some influence on subjective norm (Harvey \& Lawson, 2009).

The theory of planned behaviour (TPB), based on the work of Ajzen (1991), focuses on attitudes towards behaviour and subjective norm. It includes the construct of perceived behavioural control (PBC), which is described as the "perceived ease or difficulty of performing the behaviour" (Ajzen, 1991:183). PBC applies to behaviour in situations where an individual does not have voluntary control. TPB also takes into consideration the social systems and the roles of individual organisational members when it is used to predict and explain human behaviours such as health services utilisation, drinking, breastfeeding, smoking, and substance use (Ajzen, 1991; LaMorte, 2018).

The technology acceptance model (TAM), an adaption of the theory of reasoned action (Lee, Kozar, \& Larsen, 2003) based on the work by Davis (1989), includes two key constructs: perceived usefulness and perceived ease of use. Perceived usefulness (PU) refers to "the degree to which a person believes that using a particular system would enhance their performance." Perceived ease of use (PEOU) refers to "the degree to which a person believes that using a particular system would be free of effort" (Davis, 1989). Therefore, PEOU increases when the user believes that the system will save time and energy (Juhriyansyah, 2010).

The unified theory of acceptance and use of technology (UTAUT) extends TAM, introducing new constructs such as social influence and facilitating conditions. The UTAUT model includes a total of four key constructs, defined by Venkatesh et al (2003) as follows:

1. Performance expectancy (PE): "is the degree to which an individual believes that using the system will help him or her to attain gains in job performance (in this case, improved health care)";

2. Effort expectancy (EE): "is the degree of ease associated with the use of the system";

3. Social influence (SI): "is the degree to which an individual perceives that important others believe he or she should use the new system"; and

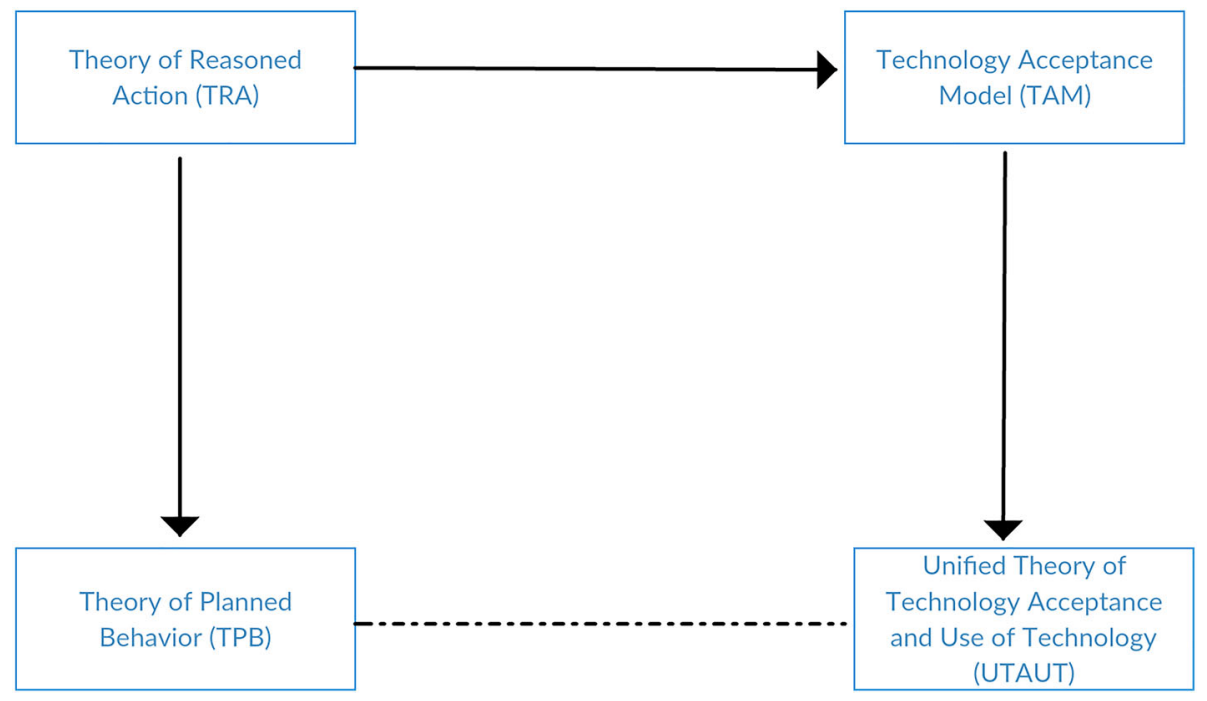

FIGURE 1 Summary of technology adoption models (Adapted from source: Sun et al., 2013) 
4. Facilitating conditions (FC): "is the degree to which an individual believes that an organisational and technical infrastructure exists to support the use of the system".

The UTAUT model was applied in a study by Petersen et al (2018) to identify factors affecting the adoption of ICT for diabetes self-management among diabetic patients in the Western Cape. The results of the study confirm that all four independent constructs inherent in the UTAUT model explain ICT adoption amongst patients with diabetes. However, despite strong support in the literature that behavioural intention is a strong indicator of actual use, Petersen et al (2018) found that this was not the case in their study. The researchers found that $67.5 \%$ of the 498 participants surveyed did not use ICT, such as m-health, to manage their diabetes, suggesting that weaknesses in the ecosystem that diabetic patients live in, and in particular, supportive facilitating conditions, may not be conducive for converting intention to use ICTs into actual use (Petersen et al., 2018).

The latter findings may be explained by Venkatesh et al (2003), who argue that the UTAUT model may present some weaknesses, viz, that it does not include external factors that can affect the performance of the behaviour. It also does not take into consideration factors such as contexts and situations that may impact usage (Venkatesh et al., 2016). Based on the latter UTAUT weaknesses identified by Venkatesh et al. (2016) and the findings of Petersen et al. (2018), the UTAUT model was deemed an unsuitable lens in this study as it would not adequately predict the challenges for the usage of ICT in this study's particular context.

\subsection{An extension to the technology acceptance model tailored for low resourced environments}

Consequently, consideration was given to the application of TAM. With TAM, attitude toward using ICT is determined by perceived usefulness and perceived ease of use. These, in turn, are determinants of behavioural intention. The relationship between perceived usefulness and behavioural intention was determined to be strongly significant (Lee et al., 2003). Moreover, an important aspect of TAM concerning this study is that it has been extended to include external factors (Venkatesh \& Davis, 2000).

Petersen, Tucker, and Pather (2017, p. 3) quoted the challenges for implementing ICT-facilitated health services, often referred to as electronic health (e-health) (Department of Health, 2015) in South Africa. The challenges included "widely differing levels of e-health maturity across and within provinces; a large number of disparate systems between which there is little or no interoperability and communication; inequity of e-health services provided and expenditure on e-health across provincial and national departments of health; limited capacity within the public sector for implementation and expensive broadband connectivity." It was further concluded that South Africa suffers from an absence of government leadership and coordination as well as no single framework to evaluate the role of $\mathrm{m}$-health and e-health tools in strengthening the health system (Department of Health, 2015).

Additionally, the challenges for implementing $\mathrm{m}$-health solutions in low resource communities are attributed mainly to the cost of access to mobile devices as well as the cost of an internet connection (Clifford, 2016; Dobson \& Jackson, 2017). Other barriers to the adoption and use of these health care tools are limited funding and poor infrastructure by government organisations (Akhlaq, McKinstry, Muhammad, \& Sheikh, 2016). South African $m$-health services are based on unsustainable business models as they rely on donor funding (Aranda-Jan, Mohutsiwa-Dibe, \& Loukanova, 2014; GSMA, 2013). These challenges for e-health and m-health success are related predominantly to technological and economic factors.

This is supported by a study evaluating a framework for the sustainability of e-health systems in South Africa, which considered three factors: social, environmental, and economic. It found that environmental factors are critical success factors for e-health sustainability, including educational factors such as low levels of education and technology illiteracy within the country (Akhlaq et al., 2016).

Cultural beliefs have also been identified in the literature as a key factor for technology acceptance and use (Dehzad, Hilhorst, de Bie, \& Claassen, 2014). Studies highlight sociocultural factors in the health care context as significant factors affecting the adoption and use of $m$-health (Beratarrechea et al., 2014). Such factors, though, are context-specific. For example, research points out that $m$-health interventions are based on developed countries and then implemented in developing countries "in a socio-cultural vacuum" (Hoque, 2016, p. 295). As such, studies into technology adoption should note that there are significant differences in systems environments between developing and developed countries (Uluç \& Çiğdem, 2016).

In light of the preceding, our premise is that external factors may offer insight into diabetic patients' intentions to use ICT. The justification for the external factors that were used in this study to expand the extended TAM model (Venkatesh \& Davis, 2000) is discussed in further detail below.

\subsection{1 | Economic factors}

El-Gayar et al. (2013) identify cost as a major reason for the rejection and abandonment of the usage of mobile applications. Cost is further broken down into the cost of obtaining a capable mobile device as well as the cost of maintaining an internet connection to sustain the use of the mobile application. El-Gayar et al (2013) and Peng, Yuan, and Holtz (2016) also identify cost of the application as a barrier, given that users will opt for 
free mobile applications rather than a subscription-based application. As such, it has been recommended that m-health interventions adopt flexible data protocols to accommodate data costs in low resource environments (Cunningham et al., 2016).

\subsection{2 | Educational factors}

Low levels of education and literacy are prominent barriers linked to the adoption and effective use of technologies for self-management of health in low resource countries (Clifford, 2016). Van Heerden et al. (2017) state that education and training programmes are a necessity as older users are unfamiliar with operating mobile devices and applications, a major barrier directly affecting the uptake and scaling of $\mathrm{m}$-health applications. In addition, Peng et al. (2016) explain that lack of application and mobile phone literacy are among the educational barriers resulting from users not actually knowing how to use mobile applications or which ones would be best suited to their needs.

\subsubsection{Sociocultural factors}

Research identifies a lack of support from family and peers as a potential barrier as this affects how active (or inactive) a patient is in terms of selfmanagement activities (Ruddock, Poindexter, Gary-Webb, Walker, \& Davis, 2016). Further, social factors that have been identified include lack of awareness regarding the availability of these mobile health applications (Dobson et al., 2017), and the patients' perception that mobile applications would be of little help or no use to them (Peng et al., 2016). Previous studies have shown that patients do not place a premium on the use of mobile applications, preferring personal contact with medical practitioners (Brinkel, Dako-Gyeke, Krämer, May, \& Fobil, 2017; Hart, Geilen, De Leeuw, \& Rutten, 2017). Therefore, the insufficiency of face-to-face interaction as well as user perception and acceptance is potential barriers to adoption and efficient use of ICT for diabetes self-management activities.

The lack of multilingual content and interface in mobile applications may also be regarded a barrier. This is an important factor in the South African context as English is not the home language of many patients, especially in the Western Cape where our study was conducted (Western Cape Language Committee, 2017). Lastly, age is identified as yet another sociocultural factor affecting health information system adoption, as older users are reluctant to adopt these new technologies, preferring traditional methods (Bawack \& Kala Kamdjoug, 2018).

\subsection{4 | Technological factors}

Akhlaq et al (2016) identify security as a factor that affects the adoption of ICT for self-management activities, particularly in terms of protecting an individual's medical and personal information. Researchers also found that older patients use basic mobile phones (Bawack \& Kala Kamdjoug, 2018) that do not have the necessary functionality to run m-health applications (van Heerden et al., 2017). A further technological factor that affects adoption is internet infrastructure or the ability of users to have access to a consistent internet connection either at their residence or in reasonable proximity to their homes. For example, in South Africa, the number of people who had internet access at home in 2016 was 9.6\% (Statistics South Africa, 2016b); by 2018, this increased only marginally to 10.4\% (Statistics South Africa, 2018).

\section{3 | Summary}

This section has provided an overview of four of the most prominent technology adoption models that prevail in the extant literature. Given that the UTAUT model has not previously been able to explain low usage of $\mathrm{m}$-health applications in low resource communities, we argue that the extended TAM model, which accounts for external factors, provides a suitable lens for this study.

Therefore, the extended TAM model shown in Figure 2 was applied in this study to investigate the challenges experienced by diabetic patients residing in the Western Cape region of South Africa. We posit that its constructs provide a basis for understanding these challenges and provide insight to $\mathrm{m}$-health solutions to mitigate the current circumstance of low adoption amongst diabetic patients in low resource communities. The adoption constructs, shown in Figure 2, form the basis of the empirical investigation.

\section{I RESEARCH DESIGN AND METHODOLOGY}

\section{1 | Research design}

The research design in this study is based on a qualitative paradigm (Jansen, 2010). This qualitative study explored the diversity of certain adoption behaviours or perceptions within a given population in the Western Cape (Jansen, 2010), establishing diversity through "the meaningful variation (relevant dimensions and values)" within the unit of analysis described below (Jansen, 2010, p. 1). 


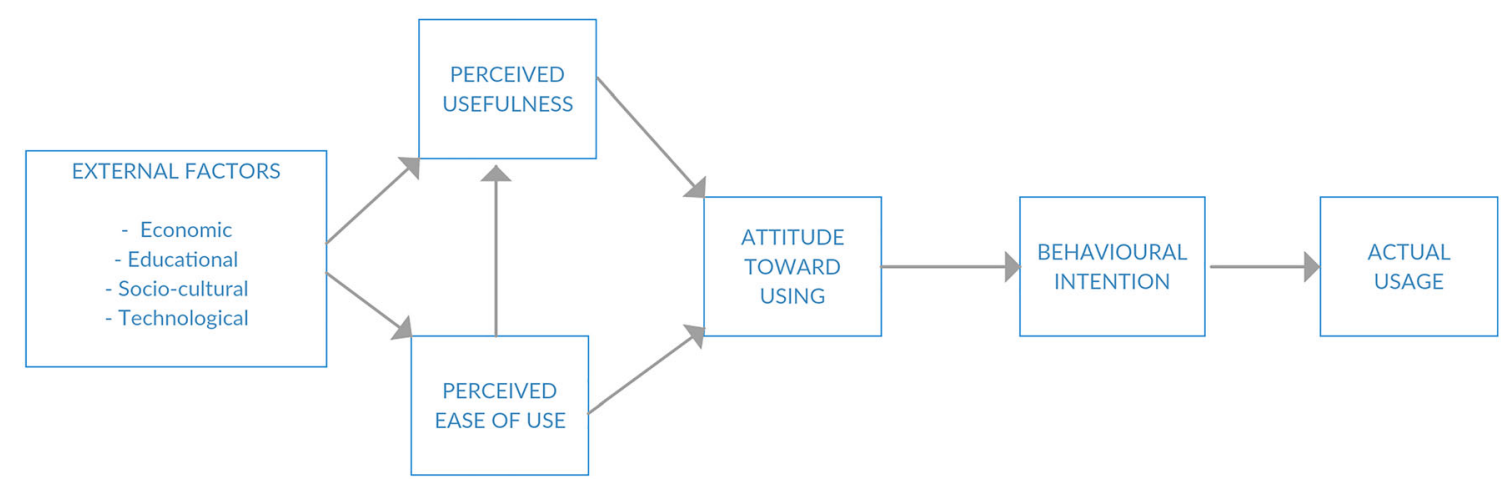

FIGURE 2 An extension of the technology acceptance model (Adapted from source: Venkatesh \& Davis, 2000)

\section{2 | Unit of analysis}

The unit of analysis for this study is composed of individuals with diabetes residing in low resource communities in the Western Cape, South Africa. The selection of the unit of analysis is premised on the understanding that the only way to understand what hinders diabetic patients from accepting and incorporating technology is to delve deeper into the perceptions, emotions, and experiences regarding the use of ICT.

\section{3 | Instrument development}

This study used a semistructured interview designed to probe diabetic patients' habits, rituals, and experiences. The interview guide used for this study was an instrument developed to determine the challenges for the adoption and use of ICT for diabetes self-management. The questions in this interview guide were based on the technology adoption constructs identified in the theoretical framework (see Section 2). The interview guide consisted of a combination of dichotomous, open-ended questions designed to ensure that the study gleaned broader insight into the participants' choices. Interview questions are presented in Table 1.

\subsection{Data sources and sampling}

This research collected qualitative data from 131 diabetic patients selected through purposive sampling (Marshall, 1996). This sample was drawn from a larger group of diabetic patients who were participants in a previous study (Petersen et al., 2018). Participants resided in predominantly low resource communities in the Cape Flats, viz, Mitchells Plain, Belhar, Khayelitsha, Athlone, Delft, and Gugulethu, all in the Western Cape.

TABLE 1 Interview questions

\begin{tabular}{|c|c|}
\hline Constructs & Questions \\
\hline External factors & $\begin{array}{l}\text { 1. Which technology (ICT) do you use to help manage your diabetes? } \\
\text { Prompt if required: Do you use a glucose testing machine? Do you search for diabetes-related information on the internet? Do } \\
\text { you use an application on your mobile phone? } \\
\text { 2. What prevents you from using ICT for managing your diabetes? } \\
\text { Prompt if required: If they don't use ICT, ask them if it's related to cost or whether it's too difficult to use. Is it anything else? } \\
\text { 3. Who gives you support for managing your diabetes? } \\
\text { Prompt if required: Their family, spouses, and children? Do they get online support, like diabetes Facebook or WhatsApp groups? } \\
\text { 4. Do you think that your skills or education impact your ability to use ICT for your diabetes? Why? } \\
\text { 5. How do you connect to the internet? } \\
\text { Prompt if required: If they say that they don't use the internet, then ask them why they don't use it. Some respondents won't } \\
\text { know that they are using the internet, so ask them whether they use Facebook or WhatsApp. }\end{array}$ \\
\hline $\begin{array}{l}\text { Technology acceptance } \\
\text { model }\end{array}$ & $\begin{array}{l}\text { 6. How do you feel about using ICT to manage your diabetes? } \\
\text { Prompt if required: Is using ICT to manage your diabetes somewhat intimidating? Do you fear to make mistakes? } \\
\text { 7. Do you find ICT useful for managing your diabetes? } \\
\text { Prompt if required: Does it help you achieve better results when you go to the doctor? } \\
\text { 8. What would make you better at managing their diabetes? } \\
\text { Prompt if required: Would or could technology make it better or easier? If so, how? } \\
\text { 9. What do you like or dislike about the current technology for managing your diabetes? } \\
\text { Prompt if required: Is it easy to use and understand? Is it easy to incorporate into your life? } \\
\text { 10. Which improvements would make you use technology more often to help improve your diabetes? }\end{array}$ \\
\hline
\end{tabular}




\section{5 | Data analysis}

This study used content analysis to identify common barriers and issues related to the adoption and use of mobile technologies for diabetes self-management (Vaismoradi, Turunen, \& Bondas, 2013). Based on the literature review, the barriers identified were economic, educational, sociocultural, and technological issues. The qualitative evidence was analysed with Atlas.ti software according to these themes to understand the barriers prohibiting successful adoption of ICT interventions. Participants' responses were then coded and grouped according to these barriers. The groups of responses were then analysed to determine the shared experiences or perceptions amongst the participants (Vaismoradi et al., 2013).

\section{6 | Ethical considerations}

The research was conducted according to the ethical and professional guidelines as specified by the University of the Western Cape (UWC). An information sheet and consent form were distributed to participants before commencement. No remuneration was provided for participation. The rights and welfare of the participants involved in the research were safeguarded by protecting the identities and interests of those involved. No clinical data (such as blood glucose readings) or unique identifiers (such as identification numbers) were collected. The researchers respected the confidentiality of the data supplied by all parties involved. Participants reserved the right not to participate or to refuse to answer any question with which they felt uncomfortable.

\section{FINDINGS}

The themes identified in this study serve to characterise the barriers and challenges experienced by individuals who have been diagnosed with diabetes. These barriers and challenges identified by the responses of participants reinforce and confirm those found in the existing literature.

\subsection{Demographics and the use of ICTs}

A total of 131 participants were interviewed. Figure 3 shows the number of people using a particular type of device according to age categories. In this study, the majority of participants was over the age of 50, using a glucose meter, with a low rate of use for m-health applications. Cell phones and mobile applications are indicated as the method of choice for self-management activities by the younger age groups.

\section{2 | Economic factors}

The economic barriers identified in this study are directly related to the cost of obtaining devices capable of supporting $\mathrm{m}$-health applications or features, as well as the cost of establishing an internet connection to manage their conditions. The cost barrier was identified across all age groups,

25

20

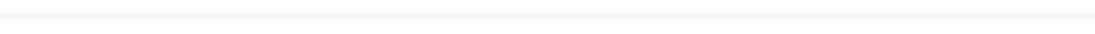

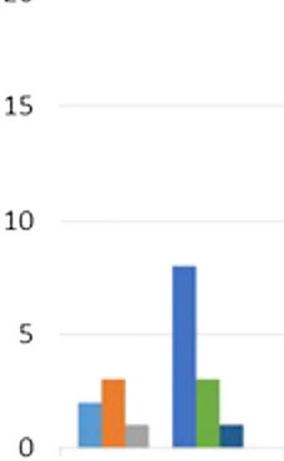

$16-24$ years

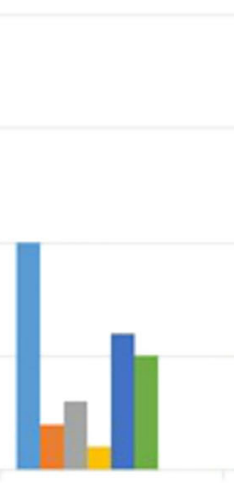

$25-34$ years

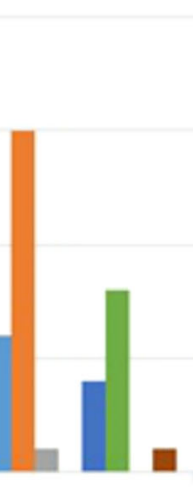

35- 49 years

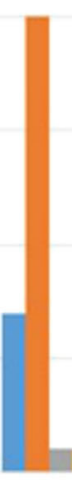

older than 50 years
Eell phone

m Glucose Meter

= Internet

naptop

Mobile Application

anone

a $P C$

a Social Media

FIGURE 3 Number of users categorised by age and device 
as responses across all age groups included, "I don't always have money to buy data" and "No sir; I do not have money for data as data is too expensive."

Several participants indicated that they could not afford the glucose meter and its necessary accessories; for example, the testing strips that are inserted into the machine. Participants lamented that these testing strips that form part of the self-management process, while quite costly, are not freely provided.

Data costs were identified as a common factor hindering participants' use of ICT. The prevailing high cost of data limits the use of these technologies to a few days per month. Even though participants have access to the necessary devices to support $m$-health applications, due to limited financial resources, they cannot afford to purchase the data needed to make use of these applications daily. This was summarised by the following response from a male, between 25 and 34 years old: "Look, lots of apps use lots of data, so I think they should create technology like an app that doesn't have any cost involved, just a normal app that you can install perhaps on your phone." Additionally, the generally dire economic circumstances of participants imply that they cannot afford the devices, such as glucose meters or mobile phones, in their totality.

\section{3 | Educational factors}

Educational factors such as a lack of electronic skills (e-skills) and a lack of awareness impacted the demand and use of $\mathrm{m}$-health applications. Participants either did not know how to use the various available technologies or did not know where to locate or obtain these technologies. This was particularly evident for older participants, as summarised by the following quote: "Honest; I can't even use my phone properly" (female, aged between 34 and 49). Participants had access to the necessary technology; however, they were unable to use it due to a lack of skills. The lack of knowledge and skills in this regard also resulted in some participants abandoning $\mathrm{m}$-health applications as they did not know how to use the application correctly and lacked support. Therefore, educational factors negatively impacted the perceived ease of use.

Alternatively, some participants showed an interest in learning how to use $\mathrm{m}$-health for self-management. This was summarised in the following quote by a participant over 50 who has some secondary education: "I never used the internet yet, but I would like to learn."

\section{4 | Sociocultural factors}

This study found that participants preferred to seek the assistance of their family, friends, and medical staff instead of using a device for self-management activities. This was highlighted by the following quote: "I don't want to play with my health and get things wrong and end up making myself sick. I'm comfortable with the doctors handling the heavy work" (female participant, older than 50).

Age was highlighted as a factor by the following quotes by male participants who were older than 50 :

"The technology is too complicated for us old people" and "I don't worry with those type of things; I'm too old." Participants further indicated that the available $m$-health applications were of no use to them as they needed assistance in operating these devices.

Participants also indicated a lack of awareness of $m$-health applications for diabetes self-management. This was summarised by the following quotes: "I didn't know that it was available for me to use" (male, 25-34) and "I was not aware that there were other technologies to use" (female, older than 50).

There is also a willingness to learn to use ICT for self-management. Several participants believed that technology and $\mathrm{m}$-health could improve their condition. For example, a typical response was "I strongly feel that technology will help us" (male participant, between 35 and 49).

\section{5 | Technological factors}

Current access to ICT tools was assessed by identifying which devices participants were using as well as the means used to connect those devices to the internet. Those who made use of multiple devices or multiple methods of connecting to the internet were requested to provide those details.

Participants identified access to internet facilities as a barrier. Internet connection in the residential areas is available; however, an individual's internet connection is dependent on the cost of data. The younger participants highlighted the use of mobile devices and various methods of internet connection, such as $\mathrm{Wi}-\mathrm{Fi}$ and prepaid data. This was summarised by the following quotes, from two female participants, aged between 35 and 49: "Wi-Fi yes, I'm using my daughter's" and "We have Wi-Fi at home, so it's convenient for me to make use of the internet."

Amongst older participants, though, a lack of know-how was identified as the main reason for not connecting to the internet. 


\section{6 | Perceived ease of use}

It is evident that participants' perceived ease of use paved the way for the rejection of ICT options such as m-health. Responses included, "I think it's too complicated and makes it too difficult for me to understand and it takes a lot of time for me to use, so because of the time, I sometimes don't feel like using it."

The effect of sociocultural factors could be mitigated by making ICT easier to use, as indicated by the following quote: "I think if it was easier to understand or use I might not rely so much on my family to help me." A male participant, between 25 and 34 who completed Grade 12, recommended the following to improve ease of use: "they could use more pictures and less text on the applications."

The data also reveal that participants perceived that $\mathrm{m}$-health could improve their conditions, if taught how to use it properly, and if it were incorporated into the local health care system. This aligns with the concept of appropriate facilitating conditions for technology adoption, described by Venkatesh et al. (2003, p. 453) as "the degree to which an individual believes that an organisational and technical infrastructure exists to support the use of the system." In this regard, the evidence indicates that diabetic patients would be more willing to use m-health if a help facility, at a local clinic, for example, was available to field queries about m-health application use.

\section{7 | Perceived usefulness}

In accordance with this theme, a commonly identified trend is that older participants generally do not use m-health applications but rely heavily on glucose meters if they have one. Participants indicated that they did not believe that using $\mathrm{m}$-health would improve their diabetes self-management. This was highlighted by the following quote: "I have had diabetes for a long time, so I'm used to taking care of myself, and I don't need any help." It was found that participants did not perceive value in using $\mathrm{m}$-health applications as they felt that their diabetes could be managed on their own.

Perceived usefulness was also negatively impacted by sociocultural factors, as one participant indicated: "I also don't see the need to have to use technology because I have my family around me for support."

Additionally, perceived ease of use negatively influenced perceived usefulness. This was highlighted by the following response of a male over 50: "I think if it was more convenient, or if the benefits were clear to me that it was important that I use other types of technology, then I would use it."

\section{8 | Attitude towards use}

Attitude towards using m-health is affected by sociocultural factors such as participants' disregard for the use of available technologies, the mistrust of technology, and participant preference for face-to-face contact with medical staff. Responses included, "If there is anything I want to know then I ask my doctor" (male participant over 50) and "I mean, sometimes things can be fabricated especially on the internet" (female participant over 50).

Additionally, attitude towards m-health use is negatively impacted by diabetic patients' perceptions of ease of use and perceived usefulness of m-health applications, clearly emphasised by a response from a female participant, over 50: "No. I tried it once, but I found that just having a decent diet and some light exercise is more than enough."

\section{9 | Behavioural intention and use}

The attitude of patients towards use of $\mathrm{m}$-health negatively affects their behavioural intention and use. This was highlighted by the following quote: "I actually don't need something to help me because I know exactly what I must do" (male, 34-49 years old).

However, it is possible that this negative behavioural intention may be mitigated if the economic conditions in relation to ICT use are improved. In this regard, participants indicated a willingness to utilise ICT should they become more cost-effective. Responses included, "I think it must take into account my needs and lifestyle, and obviously cost comes first so it must be cheaper, and I think another thing is more features for me" (male participant, older than 50) and "If technology were cheaper, I would use it every day" (female participant, between 35 and 49 ).

\section{5 | CONCLUSION}

This study sets out to investigate "What factors form barriers to ICT adoption for diabetes self-management?" Drawing on the literature, and the extended TAM model, in particular, four external factors were identified as a basis for further investigation, viz, educational, technological, economic, and sociocultural factors. These factors, together with other constructs drawn from TAM, explained how patients interact with ICT and their attitudes towards the use of ICT for diabetes self-management. The results indicate that all four external factors form barriers to ICT 
adoption for diabetes self-management in the Western Cape. The most prominent barriers relate to the financial status of diabetes patients (economic); the lack of technological literacy (education); and, finally, sociocultural factors.

The economic barriers identified in this study may be challenging to overcome, given the overall low level of economic growth of the country as a whole. However, government interventions to provide public access to broadband internet are present in all of the communities that formed the sample for this study. This may in some way mitigate problems of high internet costs. However, this is not ideal, given that the average patient needs to use a typical $\mathrm{m}$-health application daily, and therefore, less expensive access to the internet at a household level is necessary to address this barrier.

Despite the barriers, this study has found that there are diabetic patients who exhibit positive behavioural intention for ICT use. This, therefore, bodes well for future interventions at the primary health care level, which not only promote the use of $m$-health for self-management of diabetes but also incorporate education and training. The outcome of such interventions will ensure that m-health becomes an integrated part of diabetes patients' daily routine to self-manage the disease. In the long-term, this would result in improved disease management and as such contribute to the realisation of the SDGs concerning health amongst LMICs especially.

\section{1 | Summary of findings}

The economic conditions that the participants' experience do not allow for the use of expensive ICT solutions. Consequently, future ICT interventions must adapt by making use of cost-effective methods to attract diabetic patients residing in low resource communities. This is supported by a study of $\mathrm{m}$-health usage among patients and health workers in rural South Africa that found that the "use of the websites and social media was intermittent due to lack of financial ability to afford airtime" (Anstey Watkins, Goudge, Gómez-Olivé, \& Griffiths, 2018, p. 139).

The second theme identified in this study is the lack of technological literacy, as participants were either unaware that $m$-health technologies were available or are not technologically literate in terms of effective use. This finding is not peculiar to our sample population, as it is also evident in rural communities where patients did not know which health information to search for or even where to search (Anstey Watkins et al., 2018). This underscores the need for more concerted efforts to bolster technological literacy. As such, the health care system may provide an ideal context for a technology literacy programme, given that there is an inherent motivation amongst people with diabetes, who according to the evidence of this study are willing to learn how to use technology for self-management. Older diabetes patients especially will benefit from such an intervention.

The third barrier or theme identified was sociocultural factors, which include participant perceptions that mobile technologies will be of no use, the mistrust of technology as a foreign concept, and the preference for face-to-face interaction with medical staff. This stems from the lack of participant awareness concerning the benefits of $\mathrm{m}$-health applications. However, a technology literacy programme focused on diabetic patients would likely mitigate this barrier.

The final barrier identified in this study was technological challenges pertaining to the access and usage of technological devices and the availability of an internet connection. Communities in developing countries have limited resources and limited access to various technologies and infrastructure (David \& Rafiullah, 2016) posing as obstacles for required access and usage (Akhlaq et al., 2016; Beratarrechea et al., 2016). However, this study has found that participants do have access to forms of ICT, whether it is a glucose meter, mobile phone, or computer, indicating that ICT is being used and has the potential to grow within this region, especially among younger more tech-savvy patients.

\section{2 | Limitations}

This study reinforces the barriers identified in the literature, as participant responses highlighted some of the primary challenges encountered when using, or attempting to use, ICT for diabetes self-management activities. The barriers identified by this study are limited to patients with diabetes in the Western Cape and therefore may not be generalisable to the entire South African population. However, findings may be transferable to other provinces with similar economic, educational, and sociocultural contexts, such as Gauteng.

\section{3 | Future work}

Despite the barriers, this study has found that there are diabetic patients who exhibit positive perceptions of the usefulness of ICT for diabetes self-management activities. This, therefore, augers well for future interventions at the primary health care level. To promote the use of ICT, such as $\mathrm{m}$-health, for self-management of diabetes, education and training must be incorporated. The outcome of such interventions will ensure that $\mathrm{m}$-health becomes an integrated part of diabetic patients' daily routine to self-manage the condition. In the long-term, this would mean improved disease management and as such contribute to the realisation of the SDGs 3, especially LMICs.

Future ICT interventions need to ensure that the benefits of use are clearly defined and recognisable to all users, especially older patients. We are in support of studies such as Shiferaw et al. (2016) determining that the development of locally customised m-health applications can 
significantly improve health care service utilisation and positively influence self-management behaviour. Areas that could be explored further include the role of language and culture in the use of $\mathrm{m}$-health for diabetes self-management. Challenges such as economic and educational factors may be challenging to overcome in the short-term. Therefore, the use of cost-effective and sustainable options, such as positive deviance, should be considered (Petersen et al., 2017).

\section{ACKNOWLEDGEMENT}

The financial assistance of the South African National Research Foundation (NRF) towards this research is hereby acknowledged. Opinions expressed and conclusions arrived at are those of the authors and not necessarily attributable to the NRF.

\section{CONFLICT OF INTEREST}

None.

\section{ORCID}

Fazlyn Petersen (D) https://orcid.org/0000-0003-4592-2861

\section{REFERENCES}

Ajzen, I. (1991). The theory of planned behavior. Organizational Behavior and Human Decision Processes, 50, 179-211. https://doi.org/10.1016/07495978(91)90020-T

Akhlaq, A., McKinstry, B., Muhammad, K. B., \& Sheikh, A. (2016). Barriers and facilitators to health information exchange in low- and middle-income country settings: A systematic review. Health Policy and Planning., 31, 1310-1325. https://doi.org/10.1093/heapol/czw056

Alshehri, M. A. (2012). Using the UTAUT model to determine factors affecting acceptance and use of e-government services in the Kingdom of Saudi Arabia. Queensland. Retrieved from: Griffith University. https://www120.secure.griffith.edu.au/rch/file/1c7cab3e-da14-452a-8379-95387756bd56/1/ Alshehri_2013_02Thesis.pdf

American Association of Diabetes Educators. (1997). Self care behaviors. Diabetes Self-Management, 1-11. Retrieved from https://www.diabeteseducator. $\mathrm{org} / \mathrm{docs} /$ default-source/practice/practice-resources/position-statements/aade7-self-care-behaviors-position-statement.pdf?sfvrsn=6.

Anstey Watkins, J. O. T., Goudge, J., Gómez-Olivé, F. X., \& Griffiths, F. (2018). Mobile phone use among patients and health workers to enhance primary healthcare: A qualitative study in rural South Africa. Social Science and Medicine, 198(January), 139-147. https://doi.org/10.1016/j. socscimed.2018.01.011

Aranda-Jan, C. B., Mohutsiwa-Dibe, N., \& Loukanova, S. (2014). Systematic review on what works, what does not work and why of implementation of mobile health (mHealth) projects in Africa. BMC Public Health, 14(1), 188. https://doi.org/10.1186/1471-2458-14-188

Ariani, A., Koesoema, A. P., \& Soegijoko, S. (2017). Innovative healthcare applications of ICT for developing countries. In Innovative Healthcare Systems for the 21st Century. Understanding Complex Systems (pp. 15-70). Cham: Springer. https://doi.org/10.1007/978-3-319-55774-8_2

Bawack, R. E., \& Kala Kamdjoug, J. R. (2018). Adequacy of UTAUT in clinician adoption of health information systems in developing countries: The case of Cameroon. International Journal of Medical Informatics, 109(April 2017), 15-22. https://doi.org/10.1016/j.ijmedinf.2017.10.016

Bellei, E. A., Biduski, D., Cechetti, N. P., \& De Marchi, A. C. B. (2018). Diabetes mellitus m-health applications: A systematic review of features and fundamentals. Telemedicine and E-Health, 24(11), 839-852. https://doi.org/10.1089/tmj.2017.0230

Beratarrechea, A., Diez-Canseco, F., Irazola, V., Miranda, J., Ramirez-Zea, M., \& Rubinstein, A. (2016). Use of m-health technology for preventive interventions to tackle cardiometabolic conditions and other non-communicable diseases in Latin America-Challenges and opportunities. Progress in Cardiovascular Diseases., 58, 661-673. https://doi.org/10.1016/j.pcad.2016.03.003

Beratarrechea, A., Lee, A. G., Willner, J. M., Jahangir, E., Ciapponi, A., \& Rubinstein, A. (2014). The impact of mobile health interventions on chronic disease outcomes in developing countries: A systematic review. Telemedicine Journal and E-Health: The Official Journal of the American Telemedicine Association, 20(1), 75-82. https://doi.org/10.1089/tmj.2012.0328

Beratarrechea, A., Moyano, D., Irazola, V., \& Rubinstein, A. (2017). mHealth interventions to counter noncommunicable diseases in developing countries: Still an uncertain promise. Cardiology Clinics, 35(1), 13-30. https://doi.org/10.1016/j.ccl.2016.08.009

Bodenheimer, T., Lorig, K., Holman, H., \& Grumbach, K. (2002). Patient self-management of chronic disease in primary care. Jama, 288(19), 2469-2475. https://doi.org/10.1001/jama.288.19.2469

Bourne, L. T., Lambert, E. V., \& Steyn, K. (2002). Where does the black population of South Africa stand on the nutrition transition? Public Health Nutrition, 5(1A), 157-162. https://doi.org/10.1207/s15327655jchn2204_5

Brinkel, J., Dako-Gyeke, P., Krämer, A., May, J., \& Fobil, J. (2017). An investigation of users' attitudes, requirements and willingness to use mobile phonebased interactive voice response systems for seeking healthcare in Ghana: A qualitative study. Public Health, 144, 125-133. https://doi.org/ 10.1016/j.puhe.2016.11.017

Clifford, G. (2016). E-health in low to middle income countries. Journal of Medical Engineering and Technology, 40(7-8), 336-341. https://doi.org/10.1080/ 03091902.2016.1256081

Cotter, A. P., Durant, N., Agne, A. A., \& Cherrington, A. L. (2014). Internet interventions to support lifestyle modification for diabetes management: A systematic review of the evidence. Journal of Diabetes and its Complications, 28(2), 243-251. https://doi.org/10.1016/j.jdiacomp.2013.07.003 
Cunningham, P. M., Cunningham, M., van Greunen, D., Veldsman, A., Kanjo, C., Kweyu, E., \& Gebeyehu, A. (2016). Implications of baseline study findings from rural and deep rural clinics in Ethiopia, Kenya, Malawi and South Africa for the co-design of mHealth4Afrika. In 2016 IEEE Global Humanitarian Technology Conference (GHTC) (pp. 666-674). Ethiopia: IEEE.

David, S. K., \& Rafiullah, M. R. M. (2016). Innovative health informatics as an effective modern strategy in diabetes management: A critical review. International Journal of Clinical Practice, 70(6), 434-449. https://doi.org/10.1111/ijcp.12816

Davis, F. D. (1989). Perceived ease of use, and user acceptance of information technology. MIS Quarterly, 13(3), 319-340. https://doi.org/10.2307/249008

Deacon, A. J., Chee, J. J., Chang, W. J. R., \& Harbourne, B. A. (2017). Mobile applications for diabetes mellitus self-management: A systematic narrative analysis. In Successes and failures in telehealth conference (Vol. SFT-17) (pp. 17-30). Brisbane: QLD. Retrieved from. https://eprints.qut.edu.au/ 114369/1/SFT\%20Presentation\%202017\%20Final.pdf

Dehzad, F., Hilhorst, C., de Bie, C., \& Claassen, E. (2014). Adopting health apps, what's hindering doctors and patients? Health, 06(16), 2204-2217. https:// doi.org/10.4236/health.2014.616256

Department of Health. (2015). mHealth strategy. South Africa.

Didarloo, A. R., Shojaeizadeh, D., Gharaaghaji Asl, R., Habibzadeh, H., Niknami, S., \& Pourali, R. (2012). Prediction of self-management behavior among Iranian women with type 2 diabetes: Application of the theory of reasoned action along with self-efficacy (ETRA). Iranian Red Crescent Medical Journal, 14(2), 86-95. Retrieved from http://www.ncbi.nlm.nih.gov/pubmed/22737561

Dobson, P., \& Jackson, P. (2017). Using critical realism and reflexivity to explain broadband non-adoption in rural Australia. Australasian Journal of Information Systems, 21, 1-13. https://doi.org/10.3127/ajis.v21i0.1695

Dobson, R., Whittaker, R., Murphy, R., Khanolkar, M., Miller, S., Naylor, J., \& Maddison, R. (2017). The use of mobile health to deliver self-management support to young people with type 1 diabetes: A cross-sectional survey. JMIR Diabetes, 2(1), e4. https://doi.org/10.2196/diabetes.7221

El-Gayar, O., Timsina, P., Nawar, N., \& Eid, W. (2013). A systematic review of IT for diabetes self-management: Are we there yet? International Journal of Medical Informatics, 82(8), 637-652. https://doi.org/10.1016/j.ijmedinf.2013.05.006

Faruque, L. I., Wiebe, N., Ehteshami-Afshar, A., Liu, Y., Dianati-Maleki, N., Hemmelgarn, B. R., ... Tonelli, M. (2017). Effect of telemedicine on glycated hemoglobin in diabetes: A systematic review and meta-analysis of randomized trials. CMAJ, 189(9), E341-E364. https://doi.org/10.1503/cmaj.150885

Fishbein, M., \& Ajzen, I. (1975). Belief, attitude, intention, and behavior: An introduction to theory and research. MA: Addison-Wesley. Retrieved from. http:// people.umass.edu/aizen/f\&a1975.html

Gammon, D., Berntsen, G. K. R., Koricho, A. T., Sygna, K., \& Ruland, C. (2015). The chronic care model and technological research and innovation: A scoping review at the crossroads. Journal of Medical Internet Research, 17(2), e25. https://doi.org/10.2196/jmir.3547

Gillwald, A., Mothobi, O., \& Rademan, B. (2017). After access paper series: The state of ICT in South Africa. Retrieved from https://researchictafrica.net/ after-access-south-africa-state-of-ict-2017-south-africa-report_04/.

GSMA. (2013). South Africa mHealth landscape. Retrieved September 15, 2015, from http://www.gsma.com/mobilefordevelopment/wp-content/uploads/ 2013/08/South-Africa-mHealth-Landscape_June-2013.pdf.

Hart, H. E., Geilen, I. E. T. M., Leeuw De, E., \& Rutten, G. E. H. M. (2017). Internet-based self-management support for patients with well-controlled type 2 diabetes: A real-Life study. Journal of Medical Internet Research Research Protocol, 6(3), 1-13.

Harvey, J. N., \& Lawson, V. L. (2009). The importance of health belief models in determining self-care behaviour in diabetes. Diabetic Medicine, $26(1), 5-13$. https://doi.org/10.1111/j.1464-5491.2008.02628.x

van Heerden, A., Harris, D. M., van Rooyen, H., Barnabas, R. V., Ramanathan, N., Ngcobo, N., ... Comulada, W. S. (2017). Perceived mHealth barriers and benefits for home-based HIV testing and counseling and other care: Qualitative findings from health officials, community health workers, and persons living with HIV in South Africa. Social Science and Medicine, 183, 97-105. https://doi.org/10.1016/j.socscimed.2017.04.046

Hoque, M. R. (2016). An empirical study of mHealth adoption in a developing country: The moderating effect of gender concern. BMC Medical Informatics and Decision Making, 16(1), 1-10. https://doi.org/10.1186/s12911-016-0289-0

IDF. (2018). IDF Africa members. Retrieved October 22, 2018, from https://www.idf.org/our-network/regions-members/africa/members/25-south-africa.

Jansen, H. (2010). The logic of qualitative survey research and its position in the field of social research methods. Forum Qualitative Sozialforschung/Forum Qualitative Social Research, 11(2), 1-14. https://doi.org/10.1002/asna.19242220602

Juhriyansyah, D. (2010). The relationship between PU and PEOU towards the behavior intention to use new student placement (NSP) system of senior high school in Banjarmasin, South Kalimantan, Indonesia. In International Conference on Arts, Social Sciences and Technology (iCAST) (Vol. 1, pp. 15-21).

Kurnia, I. D. \& Rama, J. A. (2017). The effect of theory of reasoned action implementation on dietary and physical activity adherence in patients with diabetes mellitus type 2, 3(Inc), 233-236.

LaMorte, W. W. (2018). The theory of planned behavior. Boston: Boston University School of Public Health. Retrieved from. http://sphweb.bumc.bu.edu/ otlt/MPH-Modules/SB/BehavioralChangeTheories/BehavioralChangeTheories3.html

Lee, Y., Kozar, K. A., \& Larsen, K. R. T. (2003). The technology acceptance model: Past, present, and future. Communications of the Association for Information Systems, 12(50), 752-780. https://doi.org/10.1037/0011816

Marshall, M. N. (1996). Sampling for qualitative research. Family practice, 13(6), 522-525.

McMillan, K. A., Kirk, A., Hewitt, A., \& Macrury, S. (2017). A systematic and integrated review of mobile-based technology to promote active lifestyles in people with type 2 diabetes. Journal of Diabetes Science and Technology, 11(2), 299-307. https://doi.org/10.1177/1932296816656018

Müller, A. M., Alley, S., Schoeppe, S., \& Vandelanotte, C. (2016). The effectiveness of e-\& mHealth interventions to promote physical activity and healthy diets in developing countries: A systematic review. International Journal of Behavioral Nutrition and Physical Activity, 13(1), 109. https://doi.org/10.1186/ s12966-016-0434-2 
Mutyambizi, C., Booysen, F., Stokes, A., Pavlova, M., \& Groot, W. (2019). Lifestyle and socio-economic inequalities in diabetes prevalence in South Africa: A decomposition analysis. PLoS ONE, 14(1), e0211208. https://doi.org/10.1371/journal.pone.0211208

Nelson, L. A., Mulvaney, S. A., Gebretsadik, T., Ho, Y. X., Johnson, K. B., \& Osborn, C. Y. (2016). Disparities in the use of a mHealth medication adherence promotion intervention for low-income adults with type 2 diabetes. Journal of the American Medical Informatics Association, 23(1), 12-18. https://doi. org/10.1093/jamia/ocv082

Nundy, S., Dick, J. J., Goddu, A. P., Hogan, P., Lu, C. Y. E., Solomon, M. C., ... Peek, M. E. (2012). Using mobile health to support the chronic care model: Developing an institutional initiative. International Journal of Telemedicine and Applications, 2012, 18. https://doi.org/10.1155/2012/871925

Omisakin, F. D., \& Purity Ncama, B. (2011). Self, self-care and self-management concepts: Implications for self-management education. Educational Research, 2(12), 2141-5161. Retrieved from. http://www.interesjournals.org/ER

Peng, W., Yuan, S., \& Holtz, B. E. (2016). Exploring the challenges and opportunities of health mobile apps for individuals with type 2 diabetes living in rural communities. Telemedicine and E-Health, 22(9), 733-738. https://doi.org/10.1089/tmj.2015.0180

Petersen, F., Pather, S., \& Tucker, W. D. (2018). User acceptance of ICT for diabetes self-management in the Western Cape, South Africa. In African Conference of Information Systems and Technology (ACIST) (pp. 1-11). South Africa. Retrieved from: Cape Town. https://www.researchgate.net/publication/ 326368952

Petersen, F., Tucker, W. D., \& Pather, S. (2017). A health informatics model for user-centred design using a positive deviance approach: A case for diabetes self-management. In UCT (Ed.), African Conference on Information Systems and Technology (ACIST). South Africa. Retrieved from: Cape Town. https:// www.researchgate.net/publication/321211951_A_health_informatics_model_for_user-centred_design_using_a_positive_deviance_approach_A_case_ for_diabetes_self-management

Pullar, J., Allen, L., Townsend, N., Williams, J., Foster, C., Roberts, N., ... Wickramasinghe, K. (2018). The impact of poverty reduction and development interventions on noncommunicable diseases and their behavioural risk factors in low and lower-middle income countries: A systematic review. PLoS ONE. Public Library of Science, 13(2), e0193378. https://doi.org/10.1371/journal.pone.0193378

Rehman, H., Kamal, A. K., Sayani, S., Morris, P. B., Merchant, A. T., \& Virani, S. S. (2017). Using mobile health (mHealth) technology in the management of diabetes mellitus, physical inactivity, and smoking. Current Atherosclerosis Reports, 19(4), 16. https://doi.org/10.1007/s11883-017-0650-5

Ruddock, J. S., Poindexter, M., Gary-Webb, T. L., Walker, E. A., \& Davis, N. J. (2016). Innovative strategies to improve diabetes outcomes in disadvantaged populations. Diabetic Medicine, 33, 723-733. https://doi.org/10.1111/dme.13088

Schoeppe, S., Alley, S., Van Lippevelde, W., Bray, N. A., Williams, S. L., Duncan, M. J., \& Vandelanotte, C. (2016). Efficacy of interventions that use apps to improve diet, physical activity and sedentary behaviour: A systematic review. International Journal of Behavioral Nutrition and Physical Activity, $13(1), 127$. https://doi.org/10.1186/s12966-016-0454-y

Shiferaw, S., Spigt, M., Tekie, M., Abdullah, M., Fantahun, M., \& Dinant, G. J. (2016). The effects of a locally developed mHealth intervention on delivery and postnatal care utilization; a prospective controlled evaluation among health centres in Ethiopia. PLoS ONE, 11(7), e0158600. https://doi.org/10.1371/ journal.pone.0158600

South African History Online. (2011). Cape Town the Segregated City. Retrieved from https://www.sahistory.org.za/article/cape-town-segregated-city.

Statistics South Africa. (2016a). Mortality and causes of death in South Africa. Statistical Release P0309.3. Pretoria. https://doi.org/Statistical release P0309.3

Statistics South Africa. (2016b). Statistical release P0302 mid-year population estimates 2016. Retrieved from https://www.statssa.gov.za/publications/ P0302/P03022016.pdf.

Statistics South Africa. (2018). P0318 - General Household Survey (GHS), 2018. Retrieved from http://www.statssa.gov.za/publications/P0318/ P03182018.pdf.

Sun, Y., Wang, N., Guo, X., \& Peng, Z. (2013). Understanding the acceptance of mobile health services: A comparison and integration of alternative model. Journal of Electronic Commerce Research, 14(2), 183-201.

Tan, X., Chapman, C. D., Cedernaes, J., \& Benedict, C. (2018). Association between long sleep duration and increased risk of obesity and type 2 diabetes: A review of possible mechanisms. Sleep Medicine Reviews, 40, 127-134. https://doi.org/10.1016/j.smrv.2017.11.001

Uluç, I., \& Çiğdem, N. (2016). A comparative field study in four emerging markets; Turkey, Kingdom of Saudi Arabia, United Arab Emirates and Egypt on e-health development challenges and utilization capabilities. Sile. Retrieved from: Isik University. http://193.255.146.20:8080/xmlui/bitstream/handle/11729/ 1125/Nasiye_Cigdem_Isikdemir_Uluc.pdf?sequence=1\&isAllowed=y

Vaismoradi, M., Turunen, H., \& Bondas, T. (2013). Content analysis and thematic analysis: Implications for conducting a qualitative descriptive study. Nursing and Health Sciences, 15(3), 398-405. https://doi.org/10.1111/nhs.12048

Venkatesh, V., \& Davis, F. D. (2000). A theoretical extension of the technology acceptance model: Four longitudinal field studies. Management Science, 46(2), 186-204. https://doi.org/10.1287/mnsc.46.2.186.11926

Venkatesh, V., Morris, M. G., Davis, G. B., \& Davis, F. D. (2003). User acceptance of information technology: Toward a unified view. MIS Quarterly, 27(3), 425-478. Retrieved from. http://www.jstor.org.ezproxy.uwc.ac.za/stable/30036540?seq=1\#page_scan_tab_contents, https://doi.org/10.2307/ 30036540

Venkatesh, V., Thong, J. Y., \& Xu, X. (2016). Unified theory of acceptance and use of technology: A synthesis and the road ahead. Journal of the Association for Information Systems, 17(5), 328-376.

Waehama, W., Mcgrath, M., Korthaus, A. \& Fong, M. (2014). ICT adoption and the UTAUT model. International Conference on Educational Technology with Information Technology (ICETIS), Victoria University, Melbourne, 17(2): 24-30. Retrieved from http://www.ijitcs.com.

Western Cape Government. (2017a). Socio-economic profile. Retrieved from https://www.westerncape.gov.za/assets/departments/treasury/Documents/ Socio-economic-profiles/2016/City-of-Cape-Town/city_of_cape_town_2016_socio-economic_profile_sep-lg.pdf. 
Western Cape Government. (2017b). Switching on public Wi-Fi hotspots across the Western Cape. Retrieved August 24, 2018, from https://www. westerncape.gov.za/general-publication/switching-public-wi-fi-hotspots-across-western-cape.

Western Cape Language Committee. (2017). Western cape language policy. Department of Cultural Affairs \& Sport, Western Cape Government. Retrieved from https://www.westerncape.gov.za/general-publication/western-cape-language-policy.

World Health Organization (2016). Global report on diabetes (Vol. 1). Geneva: World Health Organisation Global report on diabetes. https://doi.org/ 10.1371/journal.pone.0127954

Zhao, J., Freeman, B., \& Li, M. (2016). Can mobile phone apps influence people's health behavior change? An evidence review. Journal of Medical Internet Research, 18(11), 1-15. https://doi.org/10.2196/jmir.5692

\section{AUTHOR BIOGRAPHIES}

Fazlyn Petersen is currently an Information Systems Lecturer at the University of the Western Cape who is working on completing her doctoral research. She believes in the practical application of theoretical knowledge to improve workplace integration and performance. Fazlyn's research interests include ICT for development (ICT4D) in health and education and entrepreneurship, as well as developing innovative teaching pedagogies to improve student learning experiences.

Afeefa Brown is currently employed as an Analyst at Accenture after completing her honours degree in Information Systems at the University of the Western Cape. She is a hardworking and diligent individual who achieved a dean's merit award.

Shaun Pather, a Fullbright scholar, works at the Department of Information Systems at the University of the Western Cape and is currently the Acting Deputy Dean: Research. His passion for supporting post-apartheid transformation objectives has evolved his research focus towards ICTs in communities and the advancement of the South African Information Society agenda. His research focuses on how information systems can be meaningfully applied in a developmental context. Prof Pather was appointed by the Minister of Communications to the ICT Policy Review Panel to establish a new framework for South Africa's ICT policies.

William D. Tucker, aka Bill, is an Associate Professor of Computer Science at the University of Western Cape (UWC) in South Africa, with nearly three decades of experience in the discipline spanning industry and academia. He is founder and director of a research group called Bridging Application and Network Gaps (BANG) that conducts multidisciplinary and transdisciplinary research into information and communication technology for development (ICT4D).

How to cite this article: Petersen F, Brown A, Pather S, Tucker WD. Challenges for the adoption of ICT for diabetes self-management in South Africa. E J Info Sys Dev Countries. 2019;e12113. https://doi.org/10.1002/isd2.12113 